\title{
Computing Realized Compound Yield With A Financial Calculator: A Note
}

Ronald L. Moy, St. John's University, USA

Ralph Terregrossa, St. John's University, USA

\begin{abstract}
This note points out that realized compound yield (RCY) has a similar concept from capital budgeting; namely, modified internal rate of return. Recognizing this relationship makes it easier to teach the concept and allows students to easily compute RCY using a financial calculator.
\end{abstract}

Keywords: yield to maturity; realized compound yield; modified internal rate of return

\section{INTRODUCTION}

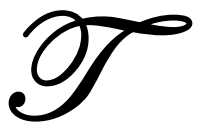

he yield to maturity (YTM) on a bond and the return that bondholders receive when they choose to reinvest the coupons can be a source of confusion to students. Many introductory finance textbooks fail to point out that the YTM, which is the rate that equates the present value of the future cash flows with the price of the bond, makes no assumption about the reinvestment of the coupons. The return that investors earn when all coupons are reinvested is known as the realized compound yield (RCY). Teaching the topic at the introductory level can be difficult because most textbooks ignore the issue.

We begin with a brief review of the realized compound yield and its relationship to the yield to maturity. In Section III, we show how RCY can easily be computed using a financial calculator. Finally, Section IV concludes the paper.

\section{REALIZED COMPOUND YIELD AND YIELD TO MATURITY}

The realized compound yield is defined as the return that bondholders receive if they reinvest all coupons at some given reinvestment rate. Following Cebula and Yang (2008, 2009), the yield to maturity is the interest rate, y, that solves the following equation:

$P=\sum_{t=1}^{N} \frac{C}{(1+y)^{t}}+\frac{F}{(1+y)^{N}}$

where $\mathrm{P}$ is the purchase price of the bond, $\mathrm{C}$ is the coupon payment, $\mathrm{F}$ is the face value and $\mathrm{N}$ is the term to maturity. The realized compound yield can be defined as:

$\mathrm{RCY}=\left[\frac{\mathrm{V}_{\mathrm{N}}}{\mathrm{P}}\right]^{\frac{1}{\mathrm{~N}}}-1$

where $V_{N}$ is the final value accumulated from the investment at maturity. As Cebula and Yang $(2008$, 2009) note, "RCY is determined exclusively by the initial investment and the final value accumulated from the investment without specifying the cash (in- or out-) flows on the investment during the investment horizon." 
Teaching the concept of RCY can be confusing for students, especially when the discussion is omitted from the textbook. Fortunately, realized compound yield, like yield to maturity, has similar concept from capital budgeting; namely, modified internal rate of return (MIRR). In modified internal rate of return, the cash flows received from the project are assumed to be reinvested at some specific reinvestment rate until the end of the project. Because realized compound yield uses the concept of MIRR, instructors who wish to teach this topic when it is omitted from the text can draw on the MIRR concept, which is gaining coverage in most introductory finance texts.

\section{COMPUTING REALIZED COMPOUND YIELD WITH A FINANCIAL CALCULATOR}

Prior to the invention of the financial calculator, the computation of yield to maturity was a tedious process that required the use of trial and error and interpolation to attain a reasonable approximation. Today, computing YTM is a painless affair using a financial calculator. The realized compound yield, on the other hand, can be more tedious to compute than the yield to maturity because the calculation requires an assumption of the reinvestment rate for the coupons.

A review of the most popular calculators from Texas Instruments, Hewlet Packard and Sharp reveals that only the TI BAII Plus Professional includes a function for computing MIRR. Because of the small difference in price, instructors may want to encourage students to consider the professional rather than the student model, which tends to be sturdier and includes some additional functions not available on the less expensive model.

Although most calculators do not include an MIRR function, the RCY for a bond is easier to compute than the MIRR for an investment project because the coupons represent an annuity. Once the reinvestment rate is established, the future value of the coupons on the maturity date can be computed in order to find RCY. Recognizing that the future value of the coupons represents an ordinary annuity allows students to easily use a financial calculator to compute this stream of payments. The RCY will be:

$$
\mathrm{RCY}=\left[\frac{\sum_{\mathrm{t}=0}^{\mathrm{N}-1}\left(1+\mathrm{y}_{\mathrm{r}}\right)^{\mathrm{t}} \mathrm{C}+\mathrm{F}}{\mathrm{P}}\right]^{\frac{1}{\mathrm{~N}}}-1
$$

In the above equation, $\Sigma\left(1+\mathrm{y}_{\mathrm{r}}\right)^{\mathrm{t}} \mathrm{C}$ represents the future value of the coupons reinvested at $\mathrm{y}_{\mathrm{r}}$. This equation can be easily solved using a financial calculator by putting the sum from the numerator into the calculator as the future value and the price of the bond as the present value and solving for the interest rate for $\mathrm{n}$-periods.

\section{An Example For Computing RCY}

Par value $=\$ 1,000$

Coupon Rate $=9 \%$

Yield to maturity $=5 \%$

$\mathrm{N}=10$

For simplicity, we assume that the bond makes annual interest payments. To compute the realized compound yield using a financial calculator requires a three-step process.

\section{Step 1: Compute the Price of the Bond}

$\mathrm{N}=10$

$\mathrm{I} / \mathrm{P}=5$

$\mathrm{PMT}=90$

$\mathrm{FV}=1,000$

CPT PV $=1,308.87$ 
Step 2: Find the FV of the Coupons using the Chosen Reinvestment Rate (in this example - 3\%)

$\mathrm{N}=10$

$\mathrm{I} / \mathrm{P}=3$

$\mathrm{PMT}=90$

$\mathrm{PV}=0$

CPT FV $=1,031.75$

Step 3: Solve for the Realized Compound Yield

$\mathrm{N}=10$

$\mathrm{FV}=1,031.75+1,000$ (Future value of coupons at reinvestment rate + par value)

$\mathrm{PMT}=0$

$\mathrm{PV}=-1,308.87$

$\mathrm{CPT} \mathrm{I} / \mathrm{P}=4.495$

To compute the RCY using the MIRR function in the TI BA II Plus Professional, the calculation requires the use of the cash flow worksheet. Using the MIRR function allows you to save a step and to change the reinvestment rate without having to recompute the future value of the invested coupons.

Step 1: Compute the Price of the Bond (see previous calculation)

Step 2: Put the Cash Flows into the Worksheet

$\mathrm{CF} 0=-1,308.87$ Enter $\downarrow$

$\mathrm{CF} 1=90$ Enter $\downarrow$

F01 $=9$ Enter $\downarrow$

$\mathrm{CF} 2=1090$ Enter $\downarrow$

$\mathrm{F} 02=1$ Enter $\downarrow$

CPT IRR (this gives us YTM)

Using the down arrow key allows us to input the reinvestment rate

$\mathrm{RI}=3$

Using the down arrow key will give MIRR $=4.495$

To change the reinvestment rate, the up arrow key can be used to scroll back to input a new RI.

\section{SUMMARY AND CONCLUSIONS}

Recognizing the dual nature of various calculations in finance makes it easier for instructors to illustrate concepts by allowing them to draw on previously covered material. The yield to maturity and internal rate of return represent just such a duality. In this note, we showed that the concept of realized compound yield and modified internal rate of return represent another identity. Instructors can use this concept to draw on the MIRR concept to teach RCY and to take advantage of the financial calculator to simplify the computation.

\section{AUTHOR INFORMATION}

Ronald L. Moy is an associate professor of economics and finance in the Tobin College of Business at St. John's University. He received his Ph.D. in economics from Rutgers University. He is a Chartered Financial Analyst, a Certified Financial Planner and the co-author of the Irwin Guide to Stocks, Bonds, Futures and Options.

Ralph Terregrossa is an associate professor of economics and finance in the Tobin College of Business at St. John's University. He received his Ph.D. in economics from the State University of New York at Binghamton. He is the 2008 recipient of the university's Teaching Excellence Award. 


\section{REFERENCES}

1. Cebula, R.J. and B.Z. Yang, 2008. "Yield to Maturity is Always Received as Promised," Journal of Economics and Finance Education. v. 7, no. 1, Summer, pp. 43-47.

2. Cebula, R.J. and B.Z. Yang, 2009. "Yield to Maturity is Always Received as Promised: A Reply," Journal of Economics and Finance Education. v. 8, no. 2, Winter, pp. 38-41. 